\title{
FIRST TSC AND DLTS MEASUREMENTS OF LOW TEMPERATURE GaAs
}

\author{
J. Muszalski, A. Babiński, K.P. Korona \\ Institute of Experimental Physics, Warsaw University \\ Hoża 69, 00-681 Warszawa, Poland \\ E. Kamińska, A. Piotrowska \\ Institute of Electron Technology \\ Al. Lotników 32/46, 02-688 Warszawa, Poland \\ M. KAMIŃsKa
Institute of Experimental Physics, Warsaw University
Hoża 69, 00-681 Warszawa, Poland \\ AND E.R. WEBER \\ University of California, Berkley, CA94720, USA
}

\begin{abstract}
The first thermally stimulated current (TSC) and deep level transient spectroscopy (DLTS) studies performed on GaAs grown by molecular beam epitaxy (MBE) at low substrate temperatures (LT GaAs) are reported. TSC experiments, conducted on as grown and $400-580^{\circ} \mathrm{C}$ annealed layers showed domination of arsenic antisite (EL2-like) defect and supported its key role in hopping conductivity. DLTS studies, performed on Si doped and annealed at $800^{\circ} \mathrm{C}$ ayers revealed substantially lower concentration of EL2-like defect and an electron trap of activation energy $\Delta E=0.38 \mathrm{eV}$ was found.
\end{abstract}

PACS numbers: 71.55.-i, 72.80.Ey

The growth of GaAs by molecular beam epitaxy (MBE) at low $\left(190-250^{\circ} \mathrm{C}\right)$ substrate temperatures (further referred to as LT GaAs layers) started three years ago. Since then LT GaAs layers have gained a big interest because of their technological importance as buffer layers for GaAs integrated circuits. It has been shown that LT GaAs is As rich with about $1 \%$ more As than Ga [1]. Such an 
off-stoichiometry should cause high concentration of defects. Up to now, arsenic antisite has been the only identified defect [2]. The aim of this work were studies of deep defects in LT GaAs layers using thermally stimulated current (TSC) and deep level transient spectroscopy (DLTS) techniques.

$\mathrm{MBE}$ GaAs layers grown at temperature $190^{\circ} \mathrm{C}$ were studied. As grown and slightly annealed $\left(400-580^{\circ} \mathrm{C}\right)$ samples had high concentration of arsenic antisite (EL2-like) defect. As calculated from optical absorption spectrum using Martin's calibration curve [3], in as grown samples there was $1 \times 10^{20} \mathrm{~cm}^{-3}$ of arsenic antisite defect while in annealed samples its concentration was about five times lower. As they had resistivity greater than $10^{2} \Omega \mathrm{cm}$ they were suitable for TSC measurements.

The results of equilibrium current and TSC are shown in Fig. 1. The equilib-

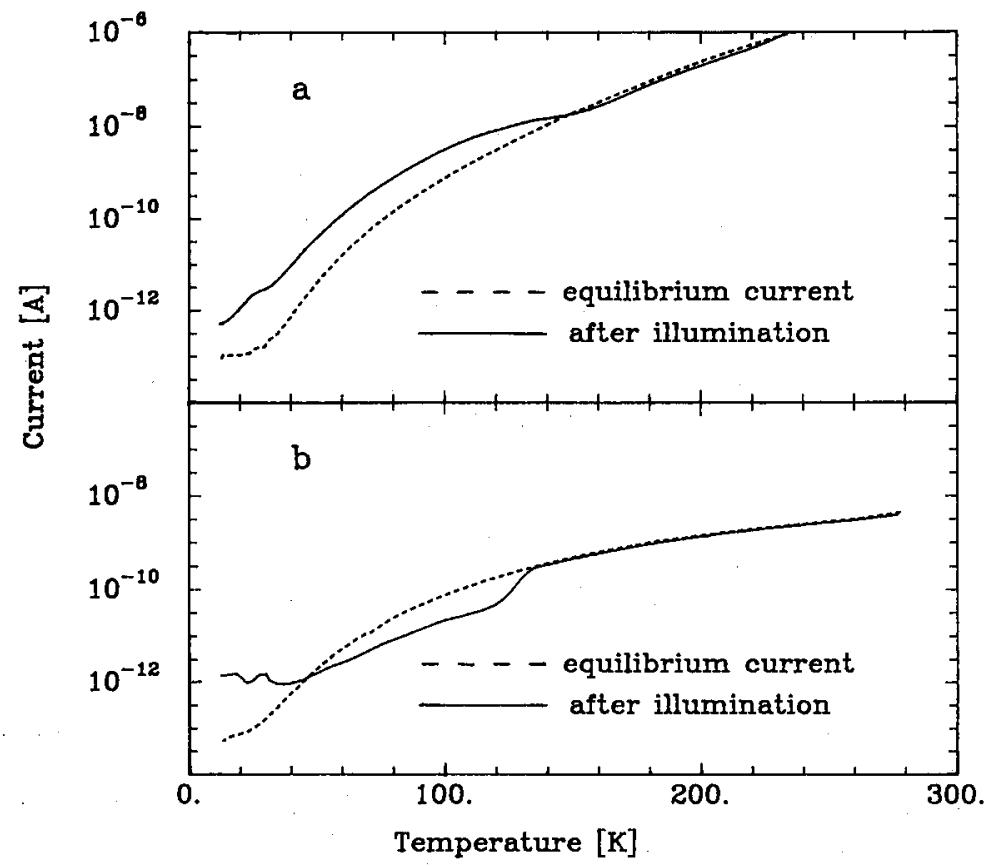

Fig. 1. The temperature dependence of the equilibrium current and TSC for as grown LT GaAs (a) and annealed at $450^{\circ} \mathrm{C}(\mathrm{b})$.

rium current was due to the hopping conductivity between arsenic antisite defects $[4,5]$. Since the Fermi level in LT GaAs was slightly above the midgap energy, TSC should detect traps in the upper half of the energy gap. However, as it is seen from Fig. 1, the shape of the thermally stimulated conductivity versus temperature was smooth showing that there were no traps with significant concentration. Only two relatively small peaks at $30 \mathrm{~K}$ and $230 \mathrm{~K}$ were observed. The peak at $30 \mathrm{~K}$ was present in as grown material and remained of the similar intensity in the annealed samples. The peak at $230 \mathrm{~K}$ was observable only in the sample annealed at $580^{\circ} \mathrm{C}$ 
(in the as grown layers as well as annealed up to $580^{\circ} \mathrm{C}$ equilibrium conductivity at $230^{\circ} \mathrm{C}$ was too high).

The significant difference between TSC and equilibrium conductivity in the temperature range below $130 \mathrm{~K}$ for all investigated layers was observed. It was found that in as grown samples TSC signal was higher than the equilibrium current, whereas in all annealed samples TSC fell to the value of about 30 times lower than the equilibrium current. It has been shown recently that in the temperature range below $130 \mathrm{~K}$, some of arsenic antisite defects in LT GaAs are in the metastable configuration after light illumination [6]. Therefore the difference between TSC and the equilibrium current below $130 \mathrm{~K}$ was obviously due to the arsenic antisite defect transformation. It needs further studies in order to understand such a difference.

The LT MBE GaAs doped during growth process with $\mathrm{Si}\left(2 \times 10^{17} \mathrm{~cm}^{-3}\right)$ was used for DLTS measurements. The samples with $\mathrm{Si}_{3} \mathrm{~N}_{4}$ protective cap $(0.2 \mu \mathrm{m})$ were annealed at temperatures between $550^{\circ} \mathrm{C}$ and $800^{\circ} \mathrm{C}$. The layers annealed at the temperature lower than $800^{\circ} \mathrm{C}$ were highly resistive. On the other hand it was found that annealing of Si doped LT GaAs starting from $800^{\circ} \mathrm{C}$ produced $n$-type layers suitable for DLTS studies. The investigated structure consisted of two MIS structures.

The obtained DLTS spectrum is presented in Fig. 2. Two peaks were de-

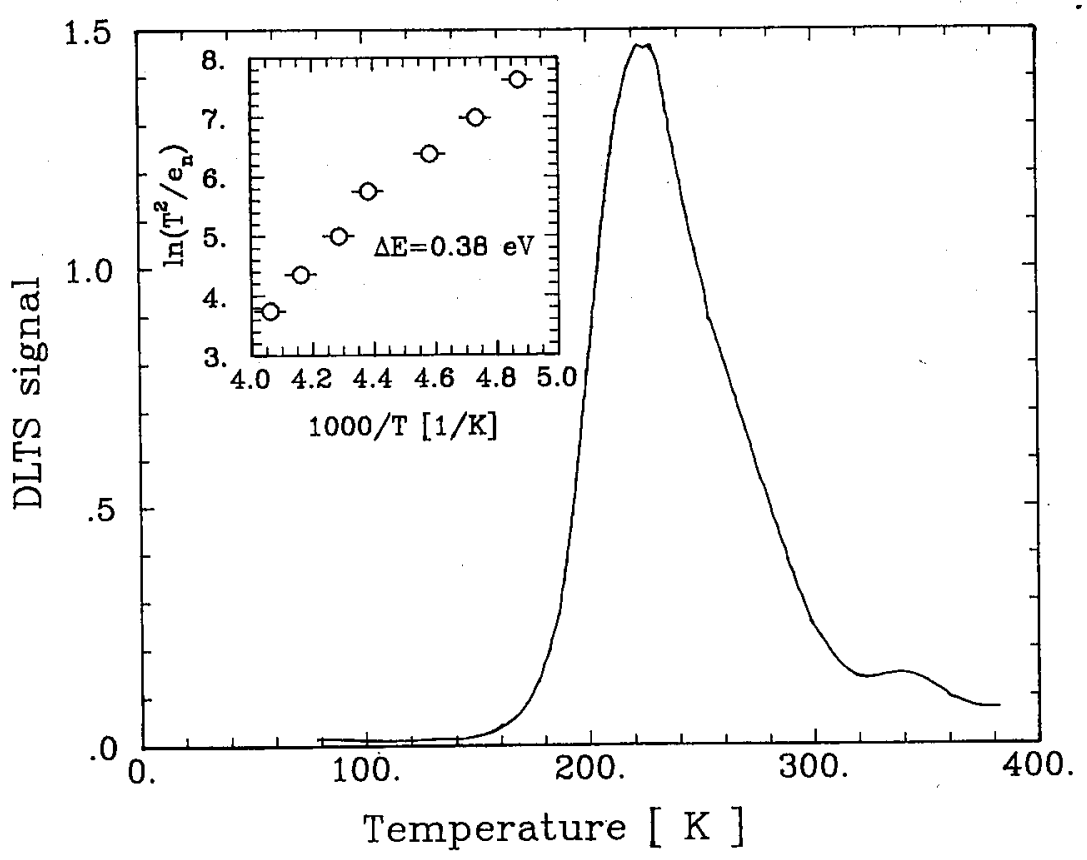

Fig. 2. DLTS spectrum of Si-doped LT GaAs annealed at $800^{\circ} \mathrm{C}$ (emission rate window $320 \mathrm{~s}^{-1}$ ). The Arrhenius plot for the dominant trap is presented in the insert. 
tected. The Arrhenius plot for the dominant trap of the activation energy $\Delta E=$ $0.38 \mathrm{eV}$ and the electron capture cross section $\sigma_{\infty}=1.0 \times 10^{-14} \mathrm{~cm}^{2}$ is presented in insert of Fig. 2. It is probably the same defect as the trap observed in MBE GaAs grown at $300^{\circ} \mathrm{C}$ [7]. No signal due to the EL2 defect was observed.

At the growth temperature of LT GaAs layers it is difficult for atoms to reach equilibrium positions since they do not have enough thermal energy for migration. Therefore, one can expect high concentration of defects in LT GaAs. From this point of view it is astonishing that except for the arsenic antisite, there were so small number of defects.

In summary, the absolute domination of the arsenic antisite defect in as grown LT GaAs layers as well as annealed up to $580^{\circ} \mathrm{C}$ was proved. The layers annealed at $800^{\circ} \mathrm{C}$ showed the supremacy of $0.38 \mathrm{eV}$ electron trap.

The authors are deeply indebted to F.W. Smith and A.R. Calawa from MIT Lincoln Laboratory for providing LT GaAs.

\section{References}

[1] F.W. Smith, C.L. Chen, G.W. Turner, M.C. Finn, L.J. Mahoney, M.J. Manfra, A.R. Calawa, in Proc. IEEE Int. Electron Devices Meeting, IEEE, New York 1988, p. 838.

[2] M. Kamińska, Z. Liliental-Weber, E.R. Weber, T. George, J.B. Kortright, F.W. Smith, B.-Y. Tsaur, A.R. Calawa, Appl. Phys. Lett. 54, 1881 (1989).

[3] G.M. Martin, Appl. Phys. Lett. 39, 747 (1981).

[4] M. Kamińska, E.R. Weber, Kin Man Yu, R. Leon, T. George; F.W. Smith, A.R. Calawa, in Proc. Semi-Insulating III-V Materials 1990, Institute of Physics, in print.

[5] D.C. Look, D.C. Walters, M.O. Manasreh, J.R. Sizelove, C.E. Stutz, K.R. Evans, submitted for publication.

[6] A. Kurpiewski, M. Palczewska, M. Kamińska, E.R. Weber, to be published.

[7] P. Blood, J.J. Harris, J. Appl. Phys. 56, 993 (1984). 